\title{
Note préliminaire sur l'incidence de la pseudo-peste aviaire dans la République du Congo
}

\author{
par R. DEPOUX et J. CHAMBRON \\ (avec la collaboration technique de Mlle E. BALDASAR)
}

L'existence de la peste aviaire, forme maladie de Newcastle, était soupçonnée depuis longtemps dans la République du Congo, en se basant sur les seules constatations cliniques; la preuve formelle de l'existence de cette maladie n'avait jamais été faite. Ces seules constatations cliniques sont incapables de donner une idée valable de la fréquence de l'affection, de nombreux animaux mourant sans lésions. La mortalité du cheptel aviaire est annuelloment importante avec une nette recrudescence pendant la saison sèche (qui coïncide ici avec la saison froide). II est classique d'en rendre la peste responsable alors que de nombreuses affections graves telles que pasteurellose, salmonellose, hémoparasitose à protozoaires, sans parler du parasitisme, doivent jover également un rôle important.

Une investigation à l'aide d'examens de laboratoire étaif donc intéressante, non seulement pour affirmer l'existence de la maladie de Newcastle au Congo, mais aussi pour étudier son incidence dans un pays où le plus souvent le diagnostic n'est pas fait à cause de l'extrême négligence des éleveurs africains et de la pauvreté de la maladie en signes pathognomoniques.

Nous avons dans ce but observé un petit foyer épidémique ef d'autre part nous avons recherché les anticorps anti-pseudopeste aviaire dans les sérums de poules prélevés en différentes régions du pays, après les grosses épidémies de la saison sèche.

\section{Matériel ef technique}

- La souche de virus de Newcastle ainsi qu'un sérum de référence provenaient du Laboratoire central de recherches vétérinaires d'Alfort.

Reçu pour publication : mars 1960.

Rev. Elev. Méd. vét. Pays trop., 1960, 13, no 1.
- Les sérums testés au cours de cette enquête épidémiologique ont été prélevés dans différents villages des régions de Brazzaville; Mindouli et Sibiti. Dans tous les cas sauf un, les poules provenaient de petits élevages familiaux africains; certes, plusieurs importants élevages européens existent bien dans le pays, mais les volailles sont régulièrement vaccinées et, de ce fait, les épidémies de pseudo-peste exceptionnelles. Dans un cas cependant nous avons prćlevé du sérum à 44 poules dans un élevage européen d'environ 200 têtes où aucune épidémie ne fut jamais signalée malgré l'absence de vaccination.

- L'isolement des virus a été fait à partir de rate de poules moribondes provenant d'un village faubourg de Brazzaville, où une épidémie avait rapidement décimé les volailles.

- Les œufs fécondés et les poules donneuses de globules rouges nous ont été fournis par une ferme du service de l'élevage du Congo.

\section{Titrage des sérums}

Les sérums furent dilués au $1 / 5$ en eau physiologique avant d'être chauffés 30 minutes à $56^{\circ} \mathrm{C}$ puis dilués du $1 / 5$ au 1/1.280 dans des plaques en perplex sous le volume de $0,25 \mathrm{~cm}^{3}$. A chaque dilution de sérum sont ajoutés d'abord $0,25 \mathrm{ml}$ de suspension de virus de référence contenant 4 doses agglutinantes, puis $0.25 \mathrm{ml}$ d'une suspension à 0,5 p. 100 de globules rouges de poule.

La lecture est faite après deux heures d'incubation à $4^{\circ} \mathrm{C}$ pour éviter les erreurs de lecture dues à l'élution très rapide des virus à la température de notre laboratoire (moyenne 28-290 C). Le titre du sérum est exprimé par l'inverse de la 
plus haute dilution du sérum provoquant 50 p. 100 d'inhibition de l'hémagglutination.

\section{Isolement des virus}

La rate de l'animal malade fut broyée de manière à faire une suspension à 10 p. 100 environ dans l'eau physiologique; puis le broyat est centrifugé à 3.000 tours pendant 20 minutes à $4{ }^{\circ} \mathrm{C}$. Le surnageant est additionné de pénicilline"et de streptomycine puis inoculé à des œufs de 11 jours par voie chorio-allantoïdienne. Après trois jours d'incubation à $37 \circ^{\circ} \mathrm{C}$, le liquide allantoïque des œufs encore vivants est passé par voie allantoïque à des œufs de 10 jours. Les passages se font ensuite toutes les 48 heures. Le titre des virus ainsi isolés est exprimé par. l'inverse de la plus haute dilution donnant encore 50 p. 100 d'hémagglutination.

\section{RÉSULTATS}

L'isolement de virus a été tenté à partir de 6 poules moribondes présentant de la prostration, une diarrhée profuse à reflets bleuâtres, de la cyanose de la crête, du larmoiement, mais aucun symptôme neurologique. L'autopsie de 4 d'entre elles a montré des lésions organiques macroscopiques pathognomoniques : pétéchies du ventricule succenturié et du cloaque; les deux autres ne présentaient pas de lésions notables. (Sur les 15 poules de ce petit élevage, 3 survécurent à l'épidémie).

Dans cinq cas l'isolement a été réussi. Le premier passage fut généralement aveugle, mais, dès le second, le titre viral atteignait 60 ou 80 . L'une des souches que nous désirions conserver, a subi 11 passages successifs et présentait régulièrement au cours des trois derniers un titre moyen de 960.

L'identification sérologique a été faite par une réaction d'inhibition de l'hémaglutination par deux sérums de même titre : le sérum de rérérence et un sérum local. Le tableau I montre bien l'identité des virus isolés au virus de référence.

Il nous a semblé intéressant de noter la virulence des souches isolées à Brazzaville pour l'œuf embryonné. L'incubation des œufs inoculés dut être limitée d̀ 40-44 heures, faute de quoi l'embryon était toujours mort au moment du prélèvement. Malgré cette incubation relative-

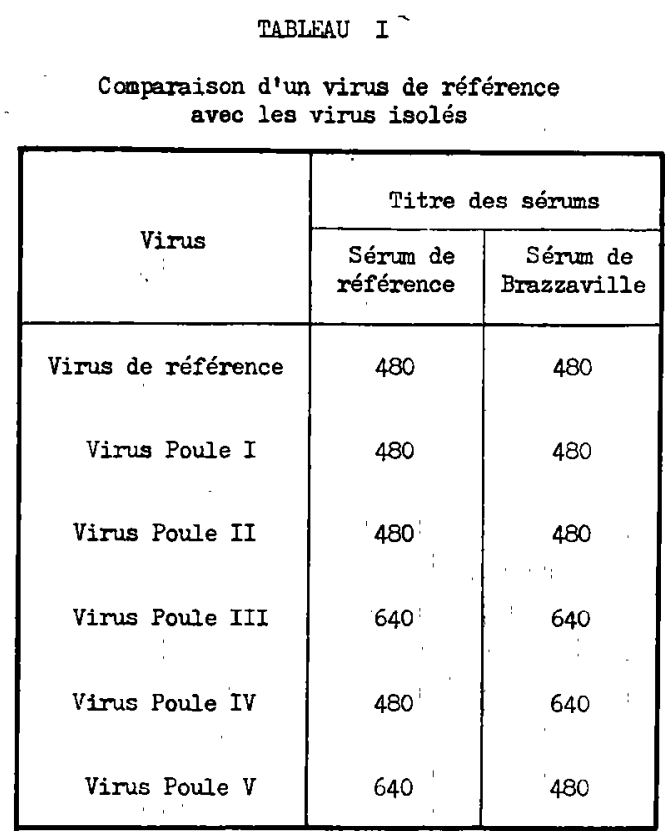

ment courte, l'embryon présentait régulièrement de nombreuses suffusions hémorragiques et le liquide allantoïque était toujours plus ou moins teinté en rose. La souche qui subit 11 passages a gardé ces caractères que ne présentait pas la souche de référence.

Enquête sérologique : Le tableau II montre que 34 p. 100 des sérums examinés ont des anticorps anti-pseudo-peste aviaire à un taux significatif.

C'est dans la région de Brazzaville que le taux de résums négatifs est le plus bas ; ces chiffres de la région de Brazzaville méritent d'être analysés ; en effet, sur les 131 sérums examinés, 44 provenaient du petit élevage européen. Or, sur ces 44 sérums, deux seulement étaient positifs et à un titre très faible : 10 , ce qui est à la limite de la spécificité de la réaction. Ces 44 sérums exclus, le pourcentage des négatifs dans les 85 restants passe de 54,2 à 31,7, chiffre de beaucoup le plus faible (Mindouli 71,4 p. 100 et Sibiti 77 p. 100). Il peut s'expliquer par la densité de villages et de population plus grande ainsi que les facilités de communication plus importantes dans la région de Brazzaville.

Quant à la considérable différence existant entre élevages européen et africains, elle découle de la manière dont ces élevages sont conçus. Dans le premier cas, les parcs sont bien tenus et 
TABLEAU II

\begin{tabular}{|c|c|c|c|c|c|c|}
\hline \multirow{2}{*}{ Régions : } & \multirow{2}{*}{$\begin{array}{l}\text { Nombre } \\
\text { de } \\
\text { sérums }\end{array}$} & \multicolumn{5}{|c|}{ Titre des sérums } \\
\hline & & 5 & 5 à 40 & 60 à 160 & 240 à 1280 & 1280 \\
\hline Brazzaville & 131 & $\begin{array}{c}71 \\
54,2 \%\end{array}$ & $\begin{array}{c}5 \\
3,8 \%\end{array}$ & $\begin{array}{c}28 \\
21,2 \%\end{array}$ & $\begin{array}{c}27 \\
20,6 \%\end{array}$ & $\begin{array}{c}0 \\
0 \%\end{array}$ \\
\hline $\begin{array}{c}\text { Brazzaville } \\
\text { Eleveges } \\
\text { africains seuls }\end{array}$ & 85 & $\begin{array}{l}27 \\
31,7 \%\end{array}$ & $\begin{array}{c}3 \\
3,5 \%\end{array}$ & $\begin{array}{c}28 \\
32,9 \%\end{array}$ & $\begin{array}{c}27 \\
31,7 \%\end{array}$ & $\begin{array}{c}0 \\
0 \%\end{array}$ \\
\hline Mindouli & 28 & $\begin{array}{c}20 \\
71,4 \%\end{array}$ & $\begin{array}{c}2 \\
7,1 \neq\end{array}$ & $\begin{array}{c}2 \\
7,1 \%\end{array}$ & $\begin{array}{c}3 \\
10,7 \%\end{array}$ & $\begin{array}{c}1 \\
3,5 \%\end{array}$ \\
\hline Sibiti & 129 & $\begin{array}{c}99 \\
7790\end{array}$ & $\begin{array}{c}0 \\
0 \%\end{array}$ & $\begin{array}{c}13 \\
10 \%\end{array}$ & $\begin{array}{c}15 \\
11,6 \%\end{array}$ & $\begin{array}{c}1 \\
0,7 \%\end{array}$ \\
\hline
\end{tabular}

isolés dans une ferme entièrement clôturée. Alors que chez les Africains, l'élevage suit encore un mode traditionnel, avec volailles en liberté, le plus souvent sans nourriture d'appoint, couchant sur les arbres ou rentrant le soir dans de petits poulaillers rarement nettoyés, jamais désinfectés. D'autre part les échanges de volailles sont fréquents de villages à villages, soit par vente. soit pour satisfaire des rites coutumiers (cadeaux, amendes, dots...).

La vaccination, toujours possible car gratuite, est rarement utilisée par les éleveurs africains qui, du fait de leur caractère indolent et fataliste, I de notre gratitude. sont peu enclins à changer de méthodes et à faire des efforts pour des animaux devant traditionnellement se débroviller seuls.

$$
\begin{gathered}
\text { Institut Pasteur de Brazzaville } \\
\text { et } \\
\text { Laboratoire de Brazzaville }
\end{gathered}
$$$$
\text { du Service de l'Elevage du Congo. }
$$

Nous tenons à remercier Monsieur le Professeur VERGE pour l'aide et les conseils qu'il nous a prodigués ; qu'il trouve ici l'expression

\section{SUMMARY}

\section{A preliminary note on the incidence of Newcastle Disease in the Congo Republic.}

Outbreaks of Newcastle Disease in flocks of poultry belonging to Africans have been suspected for a long time, but definite diagnosis has not previously been made. On five occasions recently the virus of this infection has been isolated from moribund specimens shewing typical clinical symptoms of this disease.

Further a serological survey has shown that $34 \%$ of the poultry sera examined have shown a significant titre of antibody of this infection and in the African owned back-yard flocks of Brazzaville the ratio proved to be as high as $68.1 \%$ By comparison a small unvaccinated flock in the same region owned by a European and kept under good condifions and strict isolation did not indicate any contamination. 


\section{RESUMEN}

\section{Nota preliminar sobre la incidencia de la pseudo peste aviar en la República del Congo.}

Epizootias de pseudo peste aviar han sido sospechadas desde hace tiempo en las explotaciones avícolas africanas de la Republica del Congo, pero la prueba formal de la existencia de esta enfermedad no había sido aportada todavía.

Cinco veces in virus de Newscastle fué aislado de animales moribundos, que presentaban los síntomas clínocis de una afección pestosa.

Por otra parte, una investigación serológica ha mostrado en 34 por 100 de los sueros de gallina examinados la presencia de un 'título significativo de anticuerpos anti pseudo peste aviar. El porcentagje máximo (68,1 p. 100) ha sido encontrado en las explotaciones africanas de la región de Brazzaville. Una pequeña explotación europea no vacunada de esta misma región debe a su buena instalación y a su estricto aislamiento la ausencia de toda contaminación. 